\title{
Researching about the Outdoor Space Design Adjusting to Aging Population in South-Central in China*
}

\author{
Hongzheng Xi, Qinghai Chen, Shaoyao Hu \\ Hunan University, Changsha, China \\ Email: hongzheng101@163.com
}

Received February 3, 2012; revised March 10, 2012; accepted March 21, 2012

\begin{abstract}
Aiming at the rural-urban background, the paper research content is that the outdoor space design adjusting to aging population. It is noteworthy that the "empty nest" becomes a social phenomenon in China. The community and the village are the are population most centralized region, it is also the main places that old man consume their leisure time. Outdoor space design should be suitable for the local natural climatic conditions and cultural customs. Outdoor space in Hunan of China appropriates local opened space. The high quality design of outdoor space will create conditions for social endowment and self-help endowment. Outdoor activity space is closely linked with the old people's quality of life. Function of outdoor space includes contact and the exercise as well as manual labor and pastime. Outdoor space design strategy consists of barrier-free design, identification design and activity space. The paper thinks that: "Doing to older, joy to older" is the highest state of old age. This needs the joint efforts of the family and community, needs to assume by physical space. The outdoor is the main site of activity for old man. Taking exercise, accompanying with others or pets, association and manual labor are the main content to outdoor space design.
\end{abstract}

Keywords: Empty Nest; The Older; Outdoor Space

\section{Introduction}

In China, before reform and openness, the urban population was restricted by housing, most adult children lived together with their parents. The rural population be fettered by the household registration system, young labors mostly stay in birthplace. After the marriage, they and parents constituted their united family, even if the married children had new house, it was also not far apart from their parent's. Under this circumstance, on the one hand, it is possible that the children assume the responsebility to support their parents, on the other hand, the old man can help their children at home, take care of the third generation, they are still busy and full.

With the progress of the times and the improvement of people's living standard, people are much easier to choose the way of life that they love with freedom. More and more young people are looking for a job as apart from their parents, and the new partner find love nest for themselves. The new situation results in old man staying in their old house, loneliness and dolefulness. It is noteworthy that the "empty nest" becomes a social phenomenon. To abide by the old saying "as parents alive, don't travel far away" has become not realistic, social endowment, self-help endowment put on the agenda.

${ }^{*}$ This paper is part achievements of the national natural science funds (project approval number: 51178168). Photos by authors.
The community and the village are population most centralized region, it is also the main places that old man consume their leisure time. The high quality design of outdoor space will create conditions for social endowment and self-help endowment.

This paper will discuss the function, classification and design method of outdoor space in the residential planning.

\section{Function of Outdoor Space}

\subsection{Contact and the Exercise}

Jan Gehl [1] gives a summary that outdoor activities have three types roughly: necessary, spontaneous and social. For the unemployed old people, the necessary outdoor activities are relatively small. The latter two requirements are for more. Yoshinobu Ashihara [2] divides outdoor space into two types: one is the sports space as for walking or games etc., the other is tranquil space for meditation, looking, talking and so on. Corresponding the requirement of spontaneous and social activities, just are need the exercise and stagnation spaces separately.

\subsection{Manual Labor and Pastime}

Manual labor is very necessary for everyone. Work is not only the contribution for society and family, but also is 
the affirmation of his own value. Especially, when a person gets no busy and has much spare time suddenly, he will produce huge psychological gap. Appropriate manual labor can make up for the sense of loss, to find his place.

Old man does appropriate manual labor, arranges leisure time reasonably, will be beneficial health of body and mind.

\section{Outdoor Space Design Strategy}

\subsection{Barrier-Free Design}

To the public building, its main parts of facilities for the disabled including: building entrances, traffic system, obstacle-free marks, barrier-free parking, indoor barrier-free design etc. Barrier free facilities from building entry to indoor should maintain the consistency and integrity with correspondence. Making the action inconvenience to smooth arrival, enter into and using become easy [3].

\subsubsection{Entrance Guard and Access Point}

If the public building to the barrier-free design is considered comprehensive, then, the residential design has some defective parts. As shown in Figure $\mathbf{1}$ is a comparison between gate entrance ramps of a hotel and building stairs of a dwelling house. Entrance guard settings obstruct the wheelchair entering or leaving the gate, no more ramp consideration.

\subsubsection{Road, Ramp and Step}

Roads within the residential group are mixed with person and cars, and outdoor space is also the most frequent place for the old group activities, as shown in Figure $\mathbf{2}$ is the place before apartment house as for cars, it has no outside space here for person and not consider barrier-free design further. As shown in Figure $\mathbf{3}$ is that there are some steps but has no ramp besides, pram walking across the field by lifting up and wheelchair can't even pass it.

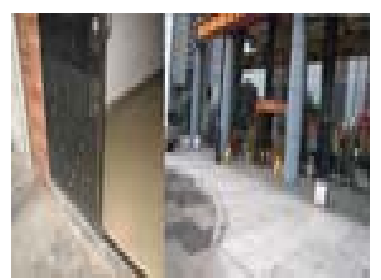

Figure 1. A comparison between gate entrance ramps of a hotel and building stairs of a dwelling house.

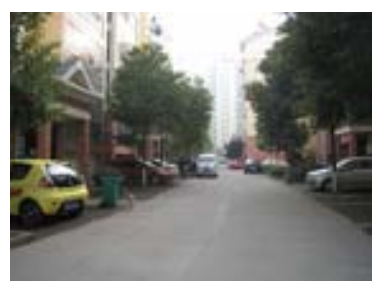

Figure 2. The place before apartment house as for cars.

\subsection{Identification Design}

Old man lost himself frequently. This is closely bound up with rapid change of city construction, unclear identification of residential group. Kevin lynch [4] in his "urban image" says that people will form the urban image from five aspects: the path, the region, the boundary, the node and the sign. They identify their environment also start from "image".

\subsubsection{The Sense of Direction of Outdoor Space}

It is easy to miss one's way if he passes by from the same house façade or the same road landscape. The old man's memory gradually tends to decrease, direction recognition ability also to drop. They often could not recall the house number of their storied building or dwelling. So, setting clearly marked, easy identification and guiding system is to guarantee the old man travel security. Its role is very important. Using different plant species, and modelling dress up community road landscape is one means to strengthen the directionality and resolution of residential road. As shown in Figure $\mathbf{4}$ is the similar residential facade, the similar path before house. The old man maybe can't point out clear where he should go.

\subsubsection{The Scale Feeling of the Outdoor Space and Node Design}

Le Corbusier [5] had the brilliant exposition: "a measure represents an era, it is the staff of spirit. Measure should correspond with The Times".

Community outdoor space should be pleasant scale. It can give a person with kind and gentle feeling. People can obtain the sense of changing climate and can feel life and the nature of the energy also.

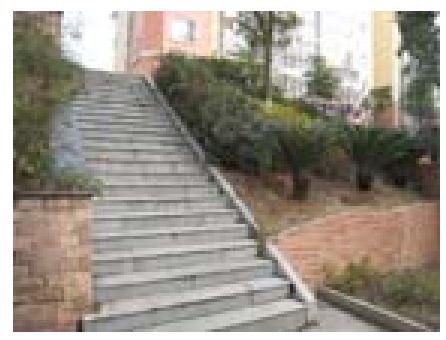

Figure 3. There are some steps bur has no ramp besides.

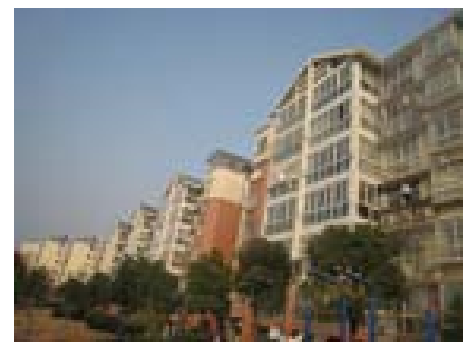

Figure 4. The similar residential façade. 
Node usually is the focus of the identification design. An old tree on the village head, a group of sculpture in the live area, all these are possess strong identification. As shown in Figure 5 is a sculpture with iconic node design.

\subsubsection{The Region and Boundary of Outdoor Space}

According to the old man's activity ability and extent, the region of outdoor space generally should be limited in the block or village with in its interior. Don't allow the vehicles pass through the region to ensure the safety for the old man. The border usually should be defined by roads and plants.

\subsection{The Design for Activity Space}

\subsubsection{Walk's Corridor}

Wandering around and walking is the main behavior characteristic of many old people. For a walk corridor, including easy to use corridor and outdoor walk way, if it can form a continuous path, then the old man will be able to go on foot in security and with no needs be care for, either in interior or outside. As shown in Figure 6 is the special corridor for walk. Unfortunately, it is not form a continuous path with intra-group road.

\subsubsection{Collective Activity Space}

Older activity center often set chess, books and periodicals room etc. Outdoor collective activities are the main recreational activities of healthy old man, such as dancing and throw a punch, etc. It is not only can strengthen their health but also be able to produce more social activities.

Collective activity space requires more open and the hard ground, not to be disturbed and also do not disturb others. Sound insulation treatments and view obstacles can all be assumed by plants or structures, buildings. As

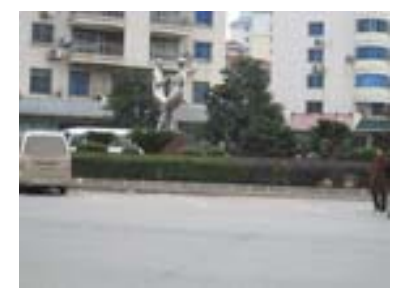

Figure 5. A sculpture with iconic node design.

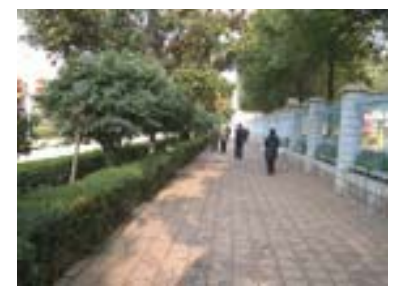

Figure 6. The special corridor for walk. shown in Figure 7 is outdoor collective activity space.

\subsubsection{Space for the Pet to Accompany Old Man}

Pets enter families, go into the old man's life, and also bring boundless joy to them. Companion animal can provide a special, multi-layered attachment to their host, the old man can also obtain the feeling of security, be concerned about, be needed and so on from it, therefore it can alleviate the pressure and the negative effects because of life changes.

The space as the shared activity area for old man and his pet should be also anti-interference, should be needed to limited area and boundary, especially to prevent young children go into to avoidable damage situations. Wide lawns, relatively quiet position is the place for the old man with his pet play together. As shown in Figure 8 is the space for the pet to accompany old man.

\subsubsection{Local Opened Space for Communication}

Local opened space can keep out sunshine, dodge rain, has good ventilation and permeability. All of this leads to adapt to the variety of outdoor climate. So it is a favorite outdoor activity place.

As shown in Figure 9 is a pavilion in a residential area without proper shelter, lack of privacy. Basically, it has no users. Figure $\mathbf{1 0}$ is a local opened corridor, both sides have sits stool, convenient to rest. But too dull linear space goes against more people stay, talking, game etc.

\subsubsection{Space for Manual Labor}

Near the community or village, hewing out the appropriate space for manual labor will be a good choice. As shown in Figure 11 is the space for manual labor. Growing vegetables, flowers, cleaning the streets... Farm labor will bring hope and joy.

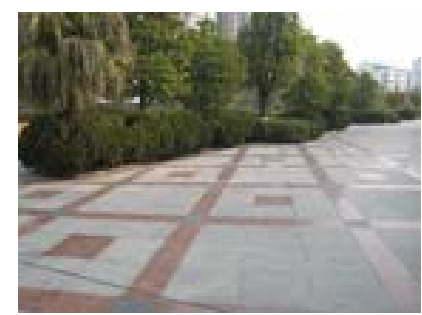

Figure 7. Outdoor collective activity space.

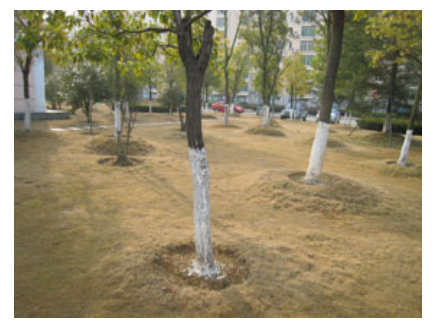

Figure 8. The space for the pet to accompany old man. 


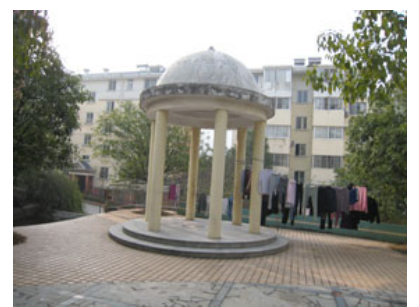

Figure 9. A pavilion in a residential area.

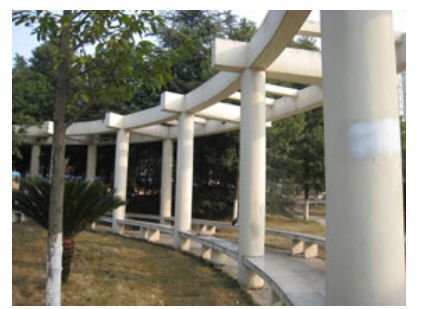

Figure 10. A local opened corridor.

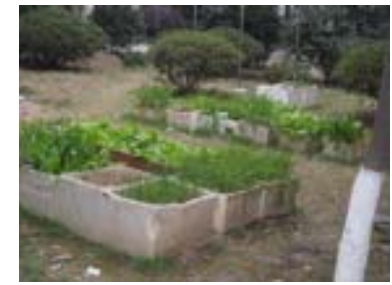

Figure 11. The space for manual labor.

\section{Summary}

"Doing to older, joy to older" is the highest state of old man. This needs the joint efforts of the family and community, needs to assume by physical space. The outdoor is the main site of activity for old man. Taking exercise, accompanying with others or pets, association and manual labor are the main content to outdoor space design.

\section{REFERENCES}

[1] G. Yang, “Communication and Space,” In: K.-H. Ren, Trans., China Architecture \& Building Press, Beijing, 1992.

[2] Y. Ashihara, “The Design of Outer Space,” In: T.-Y. Pei, Trans., China Architecture \& Building Press, Beijing, 1985.

[3] N.-Z. Li, "Barrier-Free Design for Urban Public Building Space," Master Thesis, Shandong Jianzhu University, Jinan, 2009.

[4] K. Lynch, “The Image of the City,” In: P.-F. Yi and X. He, Trans., Huaxia Press, Beijing, 2001.

[5] Le Corbusier, “Toward the New Architectural,” In: X.-W. Jing, Trans., China Architecture \& Building Press, Beijing, 1981. 